\title{
O DIREITO AO SOSSEGO: UMA ANÁLISE DO ARTIGO 1.277 DO CÓDIGO CIVIL À LUZ DA CONSTITUIÇÃO FEDERAL
}

\section{Sâmela Santana Vieira Oliveira*}

Resumo: Este trabalho se propõe a estudar o instituto do direito ao sossego nas relações de vizinhança, sob o viés da proteção ao silêncio no recesso da moradia. Analisar-se-á o artigo 1.277 do Código Civil de 2002 à luz da Constituição Federal de 1988, a qual garante a proteção ao meio ambiente, erigida ao status de direito fundamental. Serão propostos caminhos para superação de obstáculos interpretativos, estabelecendo-se diretrizes para os limites ordinários de tolerância dos moradores da vizinhança previsto no Código Civil que não importem em ofensa ao direito fundamental ao meio ambiente ecologicamente equilibrado e, consequentemente, à Lei Maior.

Palavras-chave: Direito ao Sossego. Relações de Vizinhança. Poluição Sonora. Artigo 1.277 do Código Civil. Constituição Federal.

\section{THE RIGHT TO REST: AN ANALYSIS OF ARTICLE 1.277 OF THE CIVIL CODE IN THE LIGHT OF THE FEDERAL CONSTITUTION}

\begin{abstract}
This paper proposes to study the institute of the right to the quiet in the neighborhood relations, especially the protection to the silence in the recess of the dwelling. The article 1277 of the Civil Code will be analyzed in the light of the Federal Constitution, which guarantees the protection of the environment as a fundamental right. Ways of overcoming interpretive obstacles will be proposed, establishing guidelines for the ordinary limits of tolerance provided for in the Civil Code, that do not matter in violation of the fundamental right to the ecologically balanced environment and, consequently, to the Constitution.
\end{abstract}

Keywords: Right to Rest. Neighborhood Relationships. Noise pollution. Article 1.277 of the Civil Code. Federal Constitution.

\section{INTRODUÇÃO}

\footnotetext{
* Mestranda no Programa de Pós-Graduação em Direito da Universidade Federal da Bahia - UFBA. Endereço postal: Rua Castro Alves, 124, Serraria Brasil, Feira de Santana - BA, Brasil, CEP 44003-198. E-mail: samelavieiraoliveira@gmail.com.
}

Revista Brasileira de Direito Civil em Perspectiva | e-ISSN: 2526-0243| Porto Alegre | v. 4 | n. 2 |

p. 39-61 | Jul/Dez. 2018 
A poluição sonora é considerada o problema ambiental que afeta o maior número de pessoas, depois da poluição da água e do ar, tendo se tornado um dos principais problemas ambientais dos grandes centros urbanos, considerado pela Organização Mundial de Saúde como uma das três prioridades ecológicas, segundo a qual "excessive noise seriously harms human health [...]. It can disturb sleep, cause cardiovascular and psychophysiological effects, reduce performance and provoke annoyance responses and changes in social behavior" (WORLD HEALTH ORGANIZATION, 2013).

O barulho é um mal que atinge os habitantes das cidades, constituindo motivo corriqueiro de atritos entre moradores vizinhos, sendo capaz de produzir incômodos ao bem estar das pessoas e malefícios à saúde, uma vez que gera reações que estão na base de doenças graves como disfunções cardiovasculares (LACERDA et al, 2003, p. 11).

Os ruídos incômodos que afetam os lares brasileiros representam violação ao direito humano ao silêncio e ao sossego, cujo desiderato é garantir ao cidadão o direito de viver em paz, no descanso e recesso de um lar livre de interferências externas, correlato, portanto, ao direito de vizinhança e ligado à garantia constitucional de um meio ambiente sadio, bem como à função ambiental da propriedade, "componente do princípio constitucional da função social da propriedade, analisando as interações entre o direito de propriedade e as exigências de manutenção do equilíbrio ecológico" (BORGES, 2008, p. 228).

A conquista constitucional da garantia de funcionalização da propriedade - elevada, inclusive, ao status de princípio fundamental (artigo $5^{\circ}$, inciso XXIII, CF/88) - juntamente com o princípio da dignidade da pessoa humana (artigo $1^{\circ}$, inciso III, CF/88) e o direito ao meio ambiente ecologicamente equilibrado (artigo 225, CF/88), pôs em relevo o direito ao sossego no âmbito das relações de vizinhança, embebendo-o da índole eminentemente constitucional.

Essa transformação pela qual o direito ao sossego e, via de regra, o direito de vizinhança tem passado, revela um fenômeno de transformação pelo qual o direito civil tem passado diante da necessidade de proteção do meio ambiente, no contexto de constitucionalização e relação entre

Revista Brasileira de Direito Civil em Perspectiva | e-ISSN: 2526-0243| Porto Alegre | v. 4 | n. 2 |

p. 39-61| Jul/Dez. 2018 
as mais diversas áreas do direito, que permite uma atualização e revisão de seus conceitos mais tradicionais.

Com o advento da Carta Magna de 1988, o direito ao meio ambiente sadio e ecologicamente equilibrado passou a ser garantido de forma ampla, sendo alçado, inclusive, ao status de direito fundamental.

Nesse sentido, o caput do artigo 225 da Constituição Federal prevê que "todos tem direito ao meio ambiente equilibrado, bem de uso comum do povo e essencial à sadia qualidade de vida, impondo-se ao Poder Público e à coletividade o dever de defendê-lo e preservá-lo para as presentes e futuras gerações".

Este direito, entretanto, não se coaduna com o direito de propriedade excludente, individualista e absoluto, mas com aquele geral e solidário, que cumpra sua função socioambiental.

A proteção ao meio ambiente sadio e equilibrado e o direito ao sossego possuem íntima relação, ambos objetivando resguardar o bem-estar da pessoa humana em um meio ambiente de qualidade que lhe permita levar uma vida digna, em harmonia com a natureza.

Cumpre observar, além disso, que a constitucionalização do direito infraconstitucional expressa a reinterpretação dos institutos ordinários sob uma ótica constitucional (SARMENTO, 2005). A Constituição passou a assumir a posição no vértice do sistema, lugar mais alto na hierarquia das fontes, compelindo o intérprete, diante do novo texto constitucional, a redesenhar o direito civil brasileiro à luz da Constituição.

Nesse contexto, necessário é que as disposições existentes no Código Civil de 2002 que dizem respeito ao direito ao sossego no âmbito das relações de vizinhança, especialmente o artigo 1.277, que inaugura a seção I do capítulo V, sob a epígrafe "do uso anormal da propriedade", sejam interpretadas em conformidade com os ditames constitucionais, abandonando-se a concepção tradicional de propriedade ilimitada e absoluta.

Não obstante o sossego não seja "perturbável apenas pelo som”, o sendo também "pela luz, pelo cheiro, por apreensões e choques psíquicos, ou outros motivos de inquietação"

Revista Brasileira de Direito Civil em Perspectiva | e-ISSN: 2526-0243| Porto Alegre | v. 4 | n. 2 |

p. 39-61 | Jul/Dez. 2018 
(MIRANDA, 1956, p. 305), o presente artigo destinar-se-á a analisar tão somente o viés desse direito que diz respeito à perturbação sonora, direito que poderia ser denominado de direito ao silêncio.

No decorrer deste trabalho, abordar-se-á o tema da proteção ao meio ambiente no ordenamento jurídico brasileiro. Feito isso, versar-se-á acerca do instituto do direito ao sossego e, em sequência, será feita uma análise do artigo 1.277 do Código Civil de 2002 à luz da Constituição Federal de 1988, propondo caminhos para superação de obstáculos interpretativos, na forma de pesquisa bibliográfica.

\section{A PROTEÇÃO AO MEIO AMBIENTE NO ORDENAMENTO JURÍDICO BRASILEIRO}

Com o advento da Constituição Federal de 1988, ao contrário das Constituições brasileiras predecessoras que disciplinavam apenas a competência legislativa, o ordenamento jurídico brasileiro passou a garantir o direito ao meio ambiente sadio e ecologicamente equilibrado de forma ampla, sendo alçado ao status de direito fundamental ${ }^{\dagger}$.

Isso se deu sob a influência do movimento a nível internacional no século $\mathrm{XX}$, que caminhou no sentido de reconhecer a necessidade de preservação do meio ambiente sadio que, consequentemente, foi afirmada como direito (MARÉS, 2003, p. 14).

No Brasil, a proteção ao meio ambiente é preconizada através do artigo 225 da Constituição Federal, segundo o qual "todos têm direito ao meio ambiente ecologicamente equilibrado, bem de uso comum do povo e essencial à sadia qualidade de vida, impondo-se ao

\footnotetext{
† O ordenamento jurídico brasileiro já havia tutelado o direito ambiental desde a década de 60, com o advento do Código Florestal revogado (Lei n. ${ }^{\circ}$ 4.771/65), da Lei de Proteção à Fauna (Lei n. ${ }^{\circ}$ 5.197/67), do Código de Pesca (Decreto-lei n. ${ }^{\circ}$ 221/67), da Lei que dispõe sobre a responsabilidade civil por danos nucleares e a responsabilidade criminal por atos relacionados com atividades nucleares (Lei n. ${ }^{\circ}$ 6.453/77) e da Lei de Política Nacional do Meio Ambiente (Lei n. ${ }^{\circ}$ 6.938/81), conforme historia ALMEIDA (2014, p. 73).
}

Revista Brasileira de Direito Civil em Perspectiva | e-ISSN: 2526-0243| Porto Alegre | v. 4 | n. 2 |

p. 39-61| Jul/Dez. 2018 
Poder Público e à coletividade o dever de defendê-lo e preservá-lo para as presentes e futuras gerações" (caput).

Segundo Ursula de Almeida (2014, p. 74), “o direito ao meio ambiente ecologicamente equilibrado, previsto no artigo 225, caput, da Constituição Federal de 1988, foi inspirado no Princípio 1 da Conferência de Estocolmo de 1972, pois o relacionou com a qualidade de vida e o estendeu às futuras gerações".

A Declaração de Estocolmo de 1972, por sua vez, tem, como princípio 1, o seguinte:

"O homem tem o direito fundamental à liberdade, à igualdade e ao desfrute de condições de vida adequadas em um meio ambiente de qualidade tal que lhe permita levar uma vida digna e gozar de bem-estar, tendo a solene obrigação de proteger e melhorar o meio ambiente para as gerações presentes e futuras. A este respeito, as políticas que promovem ou perpetuam o apartheid, a segregação racial, a discriminação, a opressão colonial e outras formas de opressão e de dominação estrangeira são condenadas e devem ser eliminadas".

Da mesma sorte, o Princípio 01 da Declaração do Rio de Janeiro sobre Meio Ambiente e Desenvolvimento de 1992 prevê que "os seres humanos [...] tem direito a uma vida saudável e produtiva, em harmonia com a natureza".

Observa-se, assim, que a qualidade do meio ambiente está estreitamente relacionada com o próprio direito à vida e à qualidade de vida, devendo ser observada tanto no ambiente natural e cultural como no artificial. A título de exemplo, a Constituição Federal de 1988 dispõe:

“Art. $5^{\circ}$. [...] XXIII - a propriedade atenderá a sua função social.

[...] Art. 182. A política de desenvolvimento urbano, executada pelo Poder Público municipal, conforme diretrizes gerais fixadas em lei, tem por objetivo ordenar o pleno desenvolvimento das funções sociais da cidade e garantir o bem- estar de seus habitantes.

[...]Art. 225. Todos têm direito ao meio ambiente ecologicamente equilibrado, bem de uso comum do povo e essencial à sadia qualidade de vida, impondo-se ao Poder Público e à coletividade o dever de defendê-lo e preservá-lo para as presentes e futuras gerações".

A esse respeito, HABER (2009, p. 94) defende que a qualidade de vida se trata de um tipo de complemento necessário ao meio ambiente, que exprime uma busca de qualidade após as

Revista Brasileira de Direito Civil em Perspectiva | e-ISSN: 2526-0243| Porto Alegre | v. 4 | n. 2 |

p. 39-61 | Jul/Dez. 2018 
decepções da quantidade (nível de vida), ressaltando que o ambiente concerne não apenas a natureza, mas também ao homem nos seus afazeres sociais, de trabalho e de lazer.

Portanto, o direito ambiental, a partir da dicção constitucional, trata-se de um direito social, por dizer respeito a um bem de uso comum do povo (meio ambiente), mas também de viés individual, pois integra o patrimônio jurídico de todos os indivíduos (DERANI, 2009, p. 260261).

Não se pode deixar de mencionar que o direito ambiental também se trata de direito coletivo lato sensu. Acerca da natureza do direito ao meio ambiente sadio e ecologicamente equilibrado, Gomes (2009, p. 44) afirma que se trata de "um direito difuso, pois pertence à coletividade. De modo que, sendo direito difuso indispensável à garantia da vida, o direito ao meio sadio e ecologicamente equilibrado deve ser tutelado pelo Estado, o qual deve traçar um plano de ações voltado à sua adequada e efetiva proteção".

$\mathrm{O}$ direito ao meio ambiente ecologicamente equilibrado se coaduna, portanto, com o direito de propriedade geral e solidário, que cumpra sua função social. Observa-se que os artigos 170, incisos III e VI, e 182, da Constituição Federal de 1988, inserem-se nessa linha de pensamento a qual alterou, de modo radical, o paradigma clássico absoluto da propriedade, passando do direito pleno de explorar, para o direito de explorar só e quando respeitados a saúde, segurança e sossego humano, assim como os processos e funções ecológicas essenciais, reflexo das Constituições modernas. Conforme BENJAMIN:

"A grande diferença entre as Constituições mais antigas e as atuais é que nestas o direito de propriedade aparece ambientalmente qualificado [...]. A tutela expressa do meio ambiente nas Constituições mais recentes [...] reitera a função social da propriedade, ou, para utilizar a expressão de Guilherme Purvin, enfatiza a 'dimensão ambiental da função social da propriedade"” (2007, p. 72 e 76).

Dessa forma, pode-se falar em uma função socioambiental da propriedade que decorre do comando constitucional e por ele é regulado, não sobrevivendo sem o cumprimento de seu desígnio que é o de servir à coletividade.

Revista Brasileira de Direito Civil em Perspectiva | e-ISSN: 2526-0243| Porto Alegre | v. 4 | n. 2 |

p. 39-61| Jul/Dez. 2018 


\section{O DIREITO AO SOSSEGO: UMA ANÁLISE DO ARTIGO 1.277 DO CÓDIGO CIVIL À LUZ DA \\ CONSTITUIÇÃO FEDERAL}

Para efetivação do direito ao meio ambiente ecologicamente equilibrado, a Constituição Federal, ainda, sustenta que "as condutas e atividades consideradas lesivas ao meio ambiente sujeitarão os infratores, pessoas físicas ou jurídicas, a sanções penais e administrativas, independentemente da obrigação de reparar os danos causados” (artigo 225, § $3^{\circ}$ ).

Além disso, como instrumento de proteção ao meio ambiente, a Constituição de 1988 aduz que "é competência comum da União, dos Estados, do Distrito Federal e dos Municípios: I zelar pela guarda da Constituição, das leis e das instituições democráticas e conservar o patrimônio público" e "VI - proteger o meio ambiente e combater a poluição em qualquer de suas formas" (artigo 23, incisos I e IV).

Nesse sentido, que a Lei n. ${ }^{\circ}$ 6.938/1981 (Lei da Política Nacional do Meio Ambiente), em seu artigo $3^{\circ}$, inciso III, alínea "a", definiu poluição como "a degradação da qualidade ambiental resultante de atividades que, direta ou indiretamente, prejudiquem a saúde, a segurança e o bem-estar da população".

Tal disposição normativa revela o quão próximos se encontram a proteção ao meio ambiente sadio e equilibrado e o direito ao sossego no recesso de sua moradia, o qual, em primeiro plano, objetiva resguardar o bem-estar da pessoa humana em seu principal lugar de descanso e repouso.

Isso porque, embora o meio ambiente ecologicamente equilibrado se trate de bem imaterial de uso comum do povo, este se suporta em bens materiais - como a propriedade privada - que podem ser e permanecer privados, independentemente do interesse ou direito público neles constituídos, gerando obrigações ao proprietário e direitos à coletividade. A esse respeito, MARÉS afirma que:

"Os bens imateriais de uso comum adquirem, assim, uma nova forma no ordenamento e alteram a essência da propriedade em que se assentam, porque não impõem apenas limites ao uso, mas condicionam o próprio exercício do direito, isto faz com que seja criada uma estreita relação entre os bens de uso comum imateriais, como o meio ambiente ecologicamente equilibrado e os seus suportes materiais, sejam privados ou públicos. Porque estes adquirem a função de proteger aqueles, quer dizer, rompem com a plenitude da propriedade privada" (2003, p. 47-48).

Revista Brasileira de Direito Civil em Perspectiva | e-ISSN: 2526-0243| Porto Alegre | v. 4 | n. 2 |

p. 39-61 | Jul/Dez. 2018 
ALMEIDA (2014, p.76), por sua vez, acrescenta que "independentemente da titularidade dos bens de natureza ambiental, deve ser respeitada a sua função socioambiental, bem como as limitações de uso e fruição impostas pela Constituição e pela legislação infraconstitucional".

Assim, "os direitos coletivos existem exatamente na restrição dos direitos individuais de propriedade, porque existem neles, como coisa a eles pegada, grudada de tal forma que a propriedade individual não é mais do que o suporte onde habita o coletivo", impondo, ao direito individual de propriedade, a observância aos direitos dos demais indivíduos, no qual está incluído o direito ao sossego dos vizinhos no recesso de suas moradias. Afinal, "o direito coletivo ao meio ambiente sadio engloba o direito a [...] poder viver em paz" (MARÉS, 2003, p. 14-15).

Estabelecidos tais contornos, partir-se-á, então, para a análise do instituto do direito ao sossego no âmbito das relações de vizinhança, tão somente sob o viés que diz respeito à perturbação sonora, que poderia ser denominado de direito ao silêncio.

\section{O DIREITO AO SOSSEGO}

Antes de discorrer acerca do instituto do direito ao sossego, é necessário memorar que o caráter absoluto da propriedade é retirado a partir do conceito de função social, haja vista que já não se permite ao titular do domínio se voltar contra quem quer que seja para garantia de seu direito quando descumpre esta obrigação (o que inclui a dimensão ambiental da função social da propriedade resguardada pela Constituição Federal), autorizando, com isso, o Estado a intervir para equilibrar a situação irregular verificada.

Com efeito, a função social da propriedade representa um compromisso entre a ordem liberal e a social, no qual são realinhados conceitos e práticas, com o objetivo, sobretudo, de preservar a sobrevivência humana. Isso porque "os problemas das cidades não são mais dos cidadãos individualmente, mas o acúmulo destes reflete a expressão do que se denomina ordem

Revista Brasileira de Direito Civil em Perspectiva | e-ISSN: 2526-0243| Porto Alegre | v. 4 | n. 2 |

p. 39-61| Jul/Dez. 2018 
urbanística, direito difuso", o que demonstra "um claro deslocamento do interesse a ser tutelado para o conjunto da sociedade, segundo a perspectiva solidária da justiça distributiva que caracteriza os direitos de $3^{\text {a }}$ geração" (PRESTES, 2008, p. 17 e 42).

Diante dos ditames constitucionais contemporâneos, a função social da propriedade se tornou parte integrante do próprio conteúdo da propriedade. Assim, esta última tende a traduzir uma relação entre sujeito-proprietário e bem-propriedade cujo interesse público relevante é o exercício em prol do bem comum de todos, especialmente daqueles que a rodeiam no caso das relações de vizinhança.

Assim, a propriedade compreende, em seu conteúdo e alcance, também a obrigatoriedade do atendimento de sua função social, cuja definição se mostra inseparável do requisito obrigatório de uso adequado, isto é, sem ofender, dentre outras coisas, o sossego dos que habitam prédio vizinho, através da utilização da propriedade.

Os direitos de vizinhança, nesse novo momento histórico em que a tradicional concepção individualista de propriedade deu lugar ao conceito de direito de propriedade que atenda à sua função socioambiental, resurgem então revigorados, como "verdadeiras limitações impostas por normas jurídicas a propriedades individuais, com o escopo de conciliar interesses de proprietários vizinhos, reduzindo os poderes inerentes ao domínio e de modo a regular a convivência social" (DAIBERT, 1979, p. 212).

No Brasil, o fenômeno da constitucionalização do direito civil foi um fator de grande importância para o desenvolvimento e garantia de maior proteção aos direitos de vizinhança, especialmente ao direito ao sossego, o que se deu a partir do redesenhar da matéria à luz da Constituição, ou seja, a releitura do direito civil sob os ditames dos princípios humanistas e democráticos do direito constitucional contemporâneo (TEPEDINO, 2001, p. 13).

Acerca do instituto do direito ao sossego no âmbito das relações de vizinhança, o Código Civil de 2002 o disciplinou na seção I do capítulo V, denominado "do uso anormal da propriedade". Estabeleceu, especificamente, no artigo 1.277, que:

Revista Brasileira de Direito Civil em Perspectiva | e-ISSN: 2526-0243| Porto Alegre | v. 4 | n. 2 |

p. 39-61 | Jul/Dez. 2018 
“Art. 1.277. O proprietário ou o possuidor de um prédio tem o direito de fazer cessar as interferências prejudiciais à segurança, ao sossego e à saúde dos que o habitam, provocadas pela utilização de propriedade vizinha.

Parágrafo único. Pró́bem-se as interferências considerando-se a natureza da utilização, a localização do prédio, atendidas as normas que distribuem as edificações em zonas, e os limites ordinários de tolerância dos moradores da vizinhança".

O direito ao sossego, portanto, representa verdadeira limitação do domínio pela boa convivência social, que se inspira na lealdade e boa fé, estabelecendo, ainda, deveres recíprocos entre os proprietários e/ou demais usuários de prédios vizinhos.

A título de conceituação, MATIELLO define a ofensa ao direito ao sossego como a seguir:

"Afetam o sossego as atitudes que perturbam a tranquilidade e a paz, tirando as pessoas do estado de serenidade exigível na situação concreta. Exemplos: excessivo barulho de motores, funcionamento de casas de espetáculo cujos frequentadores fazem algazarras até altas horas, utilização de aparelhos sonoros em volume incompatível com o local, festas exageradamente ruidosas em residências particulares etc." (2007, p. 805).

O direito ao sossego pode ser compreendido como um verdadeiro direito-dever, o qual envolve uma obrigação propter rem, porque se vincula aos confinantes, acompanhando a coisa, isto é, transmite-se ao sucessor a título particular e se extingue pelo abandono da coisa; e, também, uma obrigação ambulatória, haja vista que se transfere a eventuais novos ocupantes do imóvel.

Acerca disso, MONTEIRO (2007, p. 134) ensina que "[...] as limitações decorrentes da vizinhança são imanentes à propriedade. Não nascem separadamente, mas surgem simultaneamente com o próprio direito, num só ato [...], as relações de vizinhança são simples aspectos dos deveres inerentes à propriedade [...]”.

Poder-se-ia até afirmar a existência de uma contradição, pois, se é um direito, não pode ser uma limitação. Contudo, o conceito formulado se justifica, nos dizeres de RODRIGUES 


\section{O DIREITO AO SOSSEGO: UMA ANÁLISE DO ARTIGO 1.277 DO CÓDIGO CIVIL À LUZ DA \\ CONSTITUIÇÃO FEDERAL}

(2003, p. 122), em face da parêmia: jus et obligatio sunt correlata. A limitação imposta a um vizinho equivale a um direito subjetivo do outro.

Embora tenha sido preservada, no artigo 1.277, a cláusula geral prevista no artigo 554 do Código Civil de 1916 - segundo a qual "o proprietário, ou inquilino de um prédio tem o direito de impedir que o mau uso da propriedade vizinha possa prejudicar a segurança, o sossego e a saúde dos que o habitam" -, esta foi desenvolvida em mais dois dispositivos, isto é, os artigos 1.278 e 1.279 do Código Civil de 2002:

“Art. 1.278. O direito a que se refere o artigo antecedente não prevalece quando as interferências forem justificadas por interesse público, caso em que o proprietário ou o possuidor, causador delas, pagará ao vizinho indenização cabal.

Art. 1.279. Ainda que por decisão judicial devam ser toleradas as interferências, poderá o vizinho exigir a sua redução, ou eliminação, quando estas se tornarem possíveis".

Assim, infere-se que há ainda casos em que o ofendido deverá tolerar as interferências ao direito ao sossego em razão do interesse público (que se sobrepõe, por sua natureza, ao interesse particular). Nessas hipóteses, o proprietário ou o possuidor causador da perturbação deverá, em contrapartida, indenizar o vizinho prejudicado, conforme artigo 1.278 do Código Civil de 2002.

Contudo, sempre que possível, devem ser tomadas as medidas necessárias para reduzir ou mesmo eliminar as interferências, nos termos do artigo 1.279 do Código Civil. A esse respeito, MONTEIRO FILHO esclarece que:

"Se, quando a questão vier colocada, for possível ao magistrado lançar mão desses artifícios, isso deve ser feito. Se não, sem embargo da determinação para que as interferências prevaleçam, se, em um momento futuro for possível, pelo desenvolvimento tecnológico, o emprego dessas técnicas, aí sim, não obstante aquela determinação judicial, o proprietário, ou possuidor, terá direito à aplicação desses mecanismos de redução" (2002, p. 162).

O Código Civil de 2002, assim como o anterior, optou por uma formulação genérica do direito ao sossego, efetuando três importantes alterações.

Revista Brasileira de Direito Civil em Perspectiva | e-ISSN: 2526-0243| Porto Alegre | v. 4 | n. 2 |

p. 39-61 | Jul/Dez. 2018 
Primeiramente, houve a substituição da expressão "inquilino" por "possuidor", adequando-se a norma legal à interpretação que já vigorava em relação ao alcance do artigo 554 do Código Civil de 1916, segundo a qual "o que importa é a posse, a relação direta com o imóvel, seja proprietário, usufrutuário, locatário, comodatário, o que for" (MONTEIRO FILHO, 2002, p.162).

Ademais, o Código Civil de 2002 substituiu a expressão "mau uso", empregada no Código de 1916, pela locução "interferências prejudiciais", o que reflete a adoção da orientação mais técnica, uma vez que tal termo possui significado mais amplo, abrangendo as ingerências não corpóreas, não palpáveis.

Em terceiro lugar, o texto do artigo 1.277 do Novo Código Civil fala que tais interferências devem ser "provocadas pela utilização da propriedade vizinha", ou seja, trata-se, especificamente, das interferências mediatas (que começa num prédio e se propaga pela ação da natureza, até o prédio vizinho), adotando os ensinamentos de San Tiago Dantas (1939, p. 21).

As interferências prejudiciais ao sossego alheio nas relações de vizinhança podem ser classificadas em três espécies: ilegais, abusivas e lesivas.

As interferências ilegais se referem aos atos ilícitos (artigo 186 do CC/02). Neste caso, ainda que não houvesse a previsão específica do artigo 1.277 do Novo Código Civil, o prejudicado estaria protegido pelo artigo 186 que, combinado com o caput do artigo 927, do mesmo Diploma Legal, lhe garantiria o direito à devida reparação. A esse respeito, RODRIGUES acrescenta que:

\footnotetext{
"quando o proprietário prejudica o seu vizinho através de atos ilegais, o problema é simples e encontra fácil solução no preceito geral que trata dos atos ilícitos. Se o vizinho lança lixo em terreno de seu confinante, ou ateia fogo em suas plantações, o ato é ilegal, sujeitando o agente ao mister de compor o prejuízo, nos termos do art. 186 combinado com o art. 927, ambos do Código Civil” (2003, p. 124).
}

As interferências abusivas são as que, embora o causador da perturbação ao sossego se mantenha nos limites dos seus direitos de propriedade, vem a prejudicar o vizinho (muitas vezes 
sob a forma de barulho excessivo), exercendo seu direito de modo irregular, em desacordo com a sua finalidade social ou com o objetivo deliberado de prejudicar o terceiro.

São lesivas as interferências que causam dano ao vizinho, inobstante o agente não esteja fazendo uso anormal da propriedade e a atividade tenha sido até mesmo autorizada por alvará expedido pelo Poder Público.

Com efeito, a perturbação sonora (barulho) coibida pelo direito ao sossego, ao contrário do que possa parecer em uma primeira análise, não se trata de mero desconforto acústico. Os ruídos causam deterioração na qualidade de vida, reduzindo a capacidade de comunicação e memorização, provocando a perda ou diminuição da audição e do sono, envelhecimento precoce, distúrbios neurológicos, cardíacos, gástricos e circulatórios, sem que, em muitos casos, a própria vítima se dê conta.

NEPOMUCENO (1994, p. 80-81) salienta que acima do limite superior da audibilidade (o qual, para Webel, coincidia com o limiar da dor, que se encontra ao redor de $120 \mathrm{~dB}$ ), qualquer aumento de intensidade aumentará a sensação de dor. Abaixo do limiar de audibilidade, a sensação auditiva é inexistente. Entretanto, especialmente nas baixas frequências, os efeitos não auditivos podem ser percebidos, tais como náuseas, vômitos, tonturas etc., sugerindo excitação dos canais semicirculares.

FIORILLO (2003, p. 117) afirma que os prejuízos à saúde do ser humano ocorrem desde em níveis moderados de ruído, pois lentamente provocam estresse, distúrbios físicos e psicológicos, problemas auditivos e insônia, assim como sintomas secundários, desde aumento da pressão arterial, paralisação do estômago e intestino, má irrigação da pele e impotência sexual, o que se agrava em níveis maiores de barulho e poluição sonora.

Percebe-se que foi estabelecida limitação do domínio dos proprietários de prédios vizinhos em favor da harmonia social e preservação do sossego dos demais, impondo-lhes um sacrifício mútuo e necessário para que a convivência social seja possível.

Revista Brasileira de Direito Civil em Perspectiva | e-ISSN: 2526-0243| Porto Alegre | v. 4 | n. 2 |

p. 39-61 | Jul/Dez. 2018 
Com efeito, o Código Civil de 2002 não coíbe apenas o uso nocivo, anormal ou irregular da propriedade, compreendidos no artigo 1.277, mas também o uso lícito, desde que prejudicial por seu exagero cuja definição se dá caso a caso.

Interessante observação e exemplificação são feitas por LEITE:

"É certo que para se viver em sociedade, é mesmo preciso reconhecer limites e tolerar e, o ponto de equilíbrio nem sempre, é fácil de se alcançar. A jurisprudência tem procurado fixar remos capazes de aferir a normalidade no uso da propriedade:

'A utilização indevida de apartamento em edifício estritamente residencial como escritório de empresa ou mesmo de atividade profissional pelo locatário, importa em uso nocivo da propriedade por prejudicar a segurança e, sobretudo, o sossego de moradores dos demais apartamentos' (RT 708:159).

'A responsabilidade civil pelos danos de vizinhança é objetica, conduzindo a obrigação de indenizar independentemente da existência de culpa, se da atuação nociva do agente resultar dano efetivo. É necessária a comprovação de nexo causal entre a ação do vizinho e o dano sofrido pelo outro como pressuposto essencial para caracterização do dever de indenizar recaindo o ônus da prova, tratando-se de ação de indenizar, ao autor' (TA/MG, Ap. Civ. 259.054-3, relatora Desa. Jurema Brasil, DJ 1.7.98).

Recentemente a cantora Simone recebeu do STJ a confirmação das decisões de primeira e segunda instâncias que obrigaram sua vizinha, a ambientalista Fernanda Colagrossi, a retirar de seu apartamento os vinte e cinco cães que lá matinha. Pela mesma decisão, Fernanda poderia manter apenas três cães no imóvel, é a decisão tomada unicamente pela $3^{\text {a }}$. Turma do STJ e põe fim a lide que vinha sido debatida na Justiça desde 1998.

A ministra Nancy Andrighi, relatora do processo acima, afirmou que a ambientalista, apesar de não ser proprietária do imóvel, é parte legítima, uma vez que a obrigação de não causar interferências prejudiciais à segurança, ao sossego e à saúde surge da qualidade de vizinho e não de proprietário’ (REsp 622.303)” (2006, p. 02).

Entretanto, deve-se salientar que o preenchimento desse conteúdo a ser atribuído diante do caso concreto, há de ser feito à luz da Constituição, o que conduzirá o intérprete a perquirir a função social, a proteção ao meio ambiente ecologicamente equilibrado e à dignidade da pessoa humana, cuja análise será feita a seguir.

\section{O ARTIGO 1.277 DO CÓDIGO CIVIL À LUZ DA CONSTITUIÇÃO FEDERAL}

A interpretação conforme a Constituição se trata de princípio que consubstancia uma diretriz de prudência aos intérpretes da Constituição que, "em face de normas infraconstitucionais de múltiplos significados, escolham o sentido que as torne constitucionais e não aquele que

Revista Brasileira de Direito Civil em Perspectiva | e-ISSN: 2526-0243| Porto Alegre | v. 4 | n. 2 |

p. 39-61| Jul/Dez. 2018 


\section{O DIREITO AO SOSSEGO: UMA ANÁLISE DO ARTIGO 1.277 DO CÓDIGO CIVIL À LUZ DA \\ CONSTITUIÇÃO FEDERAL}

resulte na sua declaração de inconstitucionalidade" (MENDES; COELHO; BRANCO, 2009, p. 140), reforçando outros cânones interpretativos, como o princípio da supremacia da Constituição.

Nesse sentido, BARROSO acrescenta que "a interpretação conforme à Constituição não é mero preceito hermenêutico, mas, também, um mecanismo de controle de constitucionalidade pelo qual se declara ilegítima uma determinada leitura da norma legal” (1999, p. 182).

É certo que o texto da lei traz consigo diversas possibilidades interpretativas, uma vez que as palavras nela contidas são plurívocas, sendo que o seu sentido dependerá de fatores como contexto histórico, social, jurídico e econômico e, principalmente, de quem o diz. Acerca disso, ANDRADE reforça que:

“[...] é possível - e frequente - que um texto legal comporte mais de uma interpretação razoável. $\mathrm{O}$ ato de interpretar já traz, em si, naturalmente, a possibilidade de obtenção de mais de um sentido, seja qual for a técnica de redação do texto, estejam ou não presentes termos jurídicos indeterminados. Diante de textos objetivos e (aparentemente) claros, muitas vezes, mais de uma interpretação se afigura igualmente razoável ou admissível” (2008, p. 02).

Daí, a importância da aplicação do princípio da interpretação conforme a Constituição, impondo-se ao intérprete que extraia do texto legal o sentido que mais esteja em conformidade com a Lei Maior.

Sendo assim, é necessário que se extraia dele o sentido que mais se adéque aos preceitos constitucionais, ao se interpretar o artigo 1.277 do Código Civil de 2002, segundo o qual:

“Art. 1.277. O proprietário ou o possuidor de um prédio tem o direito de fazer cessar as interferências prejudiciais à segurança, ao sossego e à saúde dos que o habitam, provocadas pela utilização de propriedade vizinha.

Parágrafo único. Proíbem-se as interferências considerando-se a natureza da utilização, a localização do prédio, atendidas as normas que distribuem as edificações em zonas, e os limites ordinários de tolerância dos moradores da vizinhança".

A celeuma interpretativa que pode vir a existir em relação ao mencionado artigo reside em seu parágrafo único, especialmente na parte referente aos "limites ordinários de tolerância dos moradores da vizinhança”" (parágrafo único do art. 1.277, do CC/02).

Revista Brasileira de Direito Civil em Perspectiva | e-ISSN: 2526-0243| Porto Alegre | v. 4 | n. 2 |

p. 39-61 | Jul/Dez. 2018 
Poder-se-ia afirmar a existência de uma contradição, pois, embora se proíbam as interferências prejudiciais à segurança, ao sossego e à saúde dos que o habitam, provocadas pela utilização de propriedade vizinha, condiciona-se a aplicação do dispositivo legal aos limites ordinários de tolerância dos moradores da vizinhança. Questiona-se: quais seriam esses limites ordinários, sobretudo no que diz respeito à perturbação sonora?

Ora, à luz da Constituição Federal de 1988, sabe-se que a propriedade deve cumprir sua função socioambiental, considerando o que dispõem os artigos $5^{\circ}$, XXIII, 170, III e VI, 225 da Lei Maior, que conferiu à proteção ambiental o status de direito fundamental, dever da coletividade e do poder público, "sem a qual a integridade física e mental do indivíduo se inviabiliza, pois sem meio ambiente saudável não há sadia qualidade de vida" (ATTANASIO JUNIOR, 2012, p. 110).

Em se tratando de direito fundamental, a proteção ambiental ocupa posição no ápice da estrutura escalonada do ordenamento jurídico, como direito que vincula diretamente o legislador, o Poder Executivo e o Judiciário, representando limite de possíveis conteúdos do direito ordinário, fruto do fenômeno de irradiação das normas de direitos fundamentais a todos os ramos do direito, especialmente do efeito perante terceiros ou efeito horizontal (ALEXY, 2008, p. 520).

O direito de propriedade, nesse sentido, segundo Roxana Borges:

“[...] vem tendo sua leitura 'ecologizada' pelas necessidades de compatibilização do uso do solo com a manutenção do meio ambiente ecologicamente equilibrado. A partir da ideia de função social da propriedade, passa-se a falar em função ambiental da propriedade, no intuito de explicitar a necessidade jurídica, inclusive - de adequação do clássico, liberal e individualista direito (de propriedade) à nova, transindividual, transgeracional e solidária exigência ecológica" (2008, p. 228).

Nesse aspecto, tem-se que a "função ambiental da propriedade é dupla, pois protege não apenas os interesses difusos de defesa do meio ambiente, mas protege também o particular, enquanto proprietário, de seus próprios abusos" (BORGES, 1999, p. 90).

A Constituição Federal de 1988, em seu artigo 23, incisos I e IV, reza que "é competência comum da União, dos Estados, do Distrito Federal e dos Municípios: I - zelar pela

Revista Brasileira de Direito Civil em Perspectiva | e-ISSN: 2526-0243| Porto Alegre | v. 4 | n. 2 |

p. 39-61| Jul/Dez. 2018 


\section{O DIREITO AO SOSSEGO: UMA ANÁLISE DO ARTIGO 1.277 DO CÓDIGO CIVIL À LUZ DA \\ CONSTITUIÇÃO FEDERAL}

guarda da Constituição, das leis e das instituições democráticas e conservar o patrimônio público" e "VI - proteger o meio ambiente e combater a poluição em qualquer de suas formas" e, no artigo 24, inciso VI, estabelece que "compete à União, aos Estados e ao Distrito Federal legislar concorrentemente sobre [...] proteção do meio ambiente e controle da poluição".

Nesse sentido, acerca da poluição sonora, reza a Lei n. ${ }^{0} 9.605 / 98$ que dispõe sobre as sanções penais e administrativas derivadas de condutas e atividades lesivas ao meio ambiente, o seguinte:

\footnotetext{
"Art. 54. Causar poluição de qualquer natureza em níveis tais que resultem ou possam resultar em danos à saúde humana, ou que provoquem a mortandade de animais ou a destruição significativa da flora:

Pena - reclusão, de um a quatro anos, e multa.

$\S 1^{\circ}$ Se o crime é culposo:

Pena - detenção, de seis meses a um ano, e multa.

$\S 2^{\circ}$ Se o crime:

I - tornar uma área, urbana ou rural, imprópria para a ocupação humana;

II - causar poluição atmosférica que provoque a retirada, ainda que momentânea, dos habitantes das áreas afetadas, ou que cause danos diretos à saúde da população;

III - causar poluição hídrica que torne necessária a interrupção do abastecimento público de água de uma comunidade;

IV - dificultar ou impedir o uso público das praias;

V - ocorrer por lançamento de resíduos sólidos, líquidos ou gasosos, ou detritos, óleos ou substâncias oleosas, em desacordo com as exigências estabelecidas em leis ou regulamentos:

Pena - reclusão, de um a cinco anos.

$\S 3^{\circ}$ Incorre nas mesmas penas previstas no parágrafo anterior quem deixar de adotar, quando assim o exigir a autoridade competente, medidas de precaução em caso de risco de dano ambiental grave ou irreversível".
}

No Brasil, o Conselho Nacional do Meio Ambiente - CONAMA tem sido responsável pela produção normativa de resoluções que, especialmente no âmbito da emissão de ruídos, mudaram o panorama da política ambiental no país, especialmente no que diz respeito à poluição sonora.

Nesse contexto, o CONAMA criou a Resolução n. ${ }^{\circ}$ 01, de 08 de março de 1990, a qual dispõe sobre critérios e padrões de emissão de ruídos decorrentes de quaisquer atividades

Revista Brasileira de Direito Civil em Perspectiva | e-ISSN: 2526-0243| Porto Alegre | v. 4 | n. 2 |

p. 39-61 | Jul/Dez. 2018 
industriais, comerciais, sociais ou recreativas, inclusive as de propaganda política, bem como a Resolução nº 02, de 08 de março de 1990, que dispôs sobre o Programa Nacional de Educação e Controle da Poluição Sonora (Silêncio).

A Resolução $\mathrm{n}^{\circ}$ 01, de 1990, do CONAMA considerando que a deterioração da qualidade de vida, causada pela poluição, está sendo continuamente agravada nos grandes centros urbanos, dispôs que a emissão de ruídos, em decorrência de quaisquer atividades industriais, comerciais, sociais ou recreativas, inclusive as de propaganda política, obedecerá, no interesse da saúde, do sossego público, aos padrões, critérios e diretrizes por ela estabelecidos (item I).

Além disso, considerou "prejudiciais à saúde e ao sossego público, para os fins do item anterior, os ruídos com níveis superiores aos considerados aceitáveis pela Norma NBR 10.151 Avaliação do Ruído em Áreas Habitadas visando o conforto da comunidade, da Associação Brasileira de Normas Técnicas - ABNT" (item II da Resolução).

A NBR 10.151 da ABNT referida pelo dispositivo acima, por sua vez, fixa as condições exigíveis para avaliação da aceitabilidade do ruído em comunidades, independente da existência de reclamações.

Nesse sentido, estabelece como nível de critério de avaliação para ambientes externos em decibéis, no período diurno e noturno (sendo que, para se ter o nível de critério de avaliação para ambientes internos, corrige-se este com - $10 \mathrm{~dB}$ para janela aberta e - $15 \mathrm{~dB}$ para janela fechada), respectivamente, o seguinte:

“Áreas de sítios e fazendas, 40 e 35; área estritamente residencial urbana ou de hospitais ou de escolas, 50 e 45; área mista, predominantemente residencial, 55 e 50; área mista, com vocação comercial e administrativa, 60 e 55; área mista, com vocação recreacional, 65 e 55; área predominantemente industrial, 70 e 60" (NBR 10.151:2000 da ABNT, p. 03).

A esse respeito, a NBR 10.151 da ABNT ainda dispõe que os limites de horário para o período diurno e noturno mencionado, podem ser definidos pelas autoridades de acordo com os hábitos da população. Contudo, o período noturno não deve começar depois das 22 horas e não

Revista Brasileira de Direito Civil em Perspectiva | e-ISSN: 2526-0243| Porto Alegre | v. 4 | n. 2 |

p. 39-61| Jul/Dez. 2018 
deve terminar antes das 7 horas do dia seguinte. Caso o dia seguinte for domingo ou feriado, o término do período noturno não deve ser antes das 9 horas.

Já para o caso de execução dos projetos de construção ou de reformas de edificações para atividades heterogêneas, a Resolução n. ${ }^{\circ}$ 01/1990 do CONAMA (item III) determina que o nível de som produzido não poderá ultrapassar os níveis estabelecidos pela NBR-10.151, da ABNT, a qual dispõe sobre os níveis de ruído para conforto acústico. A título de exemplo, a citada norma determina que, nas residências, o ruído não deve passar de 35-45 decibéis e 30-40 na curva de avaliação de ruído para os dormitórios e 40-50 decibéis e 35-45 na curva de avaliação de ruído para as salas de estar.

Por oportuno, a Resolução n. ${ }^{\circ}$ 02/1990 CONAMA instituiu o Programa Nacional de Educação e Controle da Poluição Sonora, denominado "SILÊNCIO", considerando que os problemas de poluição sonora tem se agravado ao longo do tempo, nas áreas urbanas, que o som em excesso é uma séria ameaça à saúde, ao bem-estar público e a qualidade de vida e que o ser humano, cada vez mais, vem sendo submetido a condições sonoras agressivas no seu meio ambiente, e que este tem o direito garantido de conforto ambiental.

É certo que a proteção ao meio ambiente ecologicamente equilibrado, que inclui o controle da poluição sonora regulada nos dispositivos legais acima mencionados, à luz da Constituição, trata-se de exigência mínina da qual não se pode dispor ao se interpretar e aplicar o parágrafo único do artigo 1.277, do Código Civil de 2002.

Desse modo, os limites ordinários de tolerância dos moradores da vizinhança previsto no mencionado dispositivo do Código Civil não podem ser superiores ao que se configura como poluição sonora, sob pena de ferir-se o direito fundamental ao meio ambiente ecologicamente equilibrado, afrontando a Lei Maior.

\section{CONCLUSÃO}

Revista Brasileira de Direito Civil em Perspectiva | e-ISSN: 2526-0243| Porto Alegre | v. 4 | n. 2 |

p. 39-61 | Jul/Dez. 2018 
O direito ao meio ambiente ecologicamente equilibrado foi erigido ao status de direito fundamental protegido constitucionalmente, tratando-se de um que visa garantir a qualidade do meio ambiente (que diz respeito não apenas a natureza, mas também ao homem nos seus afazeres sociais, de trabalho e de lazer), relacionando-se estreitamente com o próprio direito à vida e à qualidade de vida.

A defesa do meio ambiente garantida pela Lei Maior, ao se relacionar com o Direito Civil, trouxe uma leitura ambiental para o direito de propriedade, em virtude da necessidade de compatibilizar-se o uso da terra com a manutenção do meio ambiente ecologicamente equilibrado.

Portanto, não se pode falar em cumprimento da função social da propriedade que não atenda a sua função ambiental, seja para proteger interesses difusos de defesa do meio ambiente, seja para assegurar interesses do particular, enquanto proprietário ou possuidor, de abusos. Falase, então, em uma função socioambiental da propriedade.

O direito ao meio ambiente sadio e equilibrado e o direito ao sossego possuem estreita ligação, ambos resguardam o bem-estar da pessoa humana, englobando o direito de poder viver em paz. Representam verdadeiros limites juridicamente impostos ao uso do solo, reduzindo os poderes inerentes ao domínio, harmonizando a convivência social.

Nesse aspecto, tem-se, como exemplo de confluência entre os dois institutos, o combate à perturbação sonora, a qual é extremamente prejudicial à qualidade de vida.

O parágrafo único do artigo 1.277 do Código Civil de 2002 traz consigo a possibilidade de uma celeuma interpretativa, especialmente na parte referente aos "limites ordinários de tolerância dos moradores da vizinhança", ao qual condiciona a proteção ao sossego no recesso da moradia. $\mathrm{O}$ texto da lei, assim, traz consigo diversas possibilidades interpretativas.

Todavia, o princípio da interpretação conforme a Constituição preconiza que se extraia da norma infraconstitucional o sentido que mais se adéque aos preceitos constitucionais, a fim de que a interpretação não resulte na sua declaração de inconstitucionalidade.

Revista Brasileira de Direito Civil em Perspectiva | e-ISSN: 2526-0243| Porto Alegre | v. 4 | n. 2 |

p. 39-61| Jul/Dez. 2018 
À luz da Constituição, a proteção ao meio ambiente ecologicamente equilibrado, que inclui o controle da poluição sonora regulada em normas infraconstitucionais, trata-se de exigência mínina da qual não se pode dispor ao se interpretar e aplicar o parágrafo único do artigo 1.277, do Código Civil de 2002.

Desse modo, os limites ordinários de tolerância dos moradores da vizinhança previsto no mencionado dispositivo do Código Civil não podem ser superiores ao que se configura como poluição sonora, sob pena de ferir-se o direito fundamental ao meio ambiente ecologicamente equilibrado, afrontando a Constituição Federal de 1988.

\section{REFERÊNCIAS}

ALEXY, Robert. Teoria dos direitos fundamentais. São Paulo: Malheiros, 2008.

ALMEIDA, Ursula Ribeiro de. Tutela de urgência no direito ambiental: instrumento de efetivação do princípio de precaução. 2014. 240 f. Dissertação (Mestrado em Direito) Faculdade de Direito, Universidade de São Paulo, São Paulo, 2014. Disponível em: <http://www.teses.usp.br/teses/disponiveis/2/2137/tde-09022015-163958/pt-br.php>. Acesso em 16 jul. 2018.

ANDRADE, André Gustavo C. de. Dimensões da interpretação conforme a Constituição. Disponível em: < http://www.tjrj.jus.br/c/document_library/get_file?uuid=d4d29181-ba2a-42f183da-fd93a5b86397\&groupId=10136 >. Acesso em 18 jul. 2018.

ATTANASIO JUNIOR, Mario Roberto. Teoria crítica e direito ambiental. 2012. 153 f. Tese (Doutorado em Direito) - Faculdade de Direito, Universidade de São Paulo, São Paulo, 2012. Disponível em: < http://www.teses.usp.br/teses/disponiveis/2/2139/tde-07062013-142406/ptbr.php >. Acesso em 16 jul. 2018.

BARROSO, Luís Roberto. Interpretação e Aplicação da Constituição. $3^{a}$ ed. São Paulo: Saraiva, 1999.

BORGES, Roxana Cardoso Brasileiro. A proteção do meio ambiente frente ao direito de propriedade: a função ambiental da propriedade rural. 1999. 229 f. Dissertação (Mestrado em Direito) - Faculdade de Direito, Universidade Federal de Santa Catarina, Santa Catarina, 1999. Disponível em:

Revista Brasileira de Direito Civil em Perspectiva | e-ISSN: 2526-0243| Porto Alegre | v. 4 | n. 2 |

p. 39-61 | Jul/Dez. 2018 
<https://repositorio.ufsc.br/xmlui/bitstream/handle/123456789/80740/142161.pdf?sequence=1\&i sAllowed=y>. Acesso em 16 jul. 2018.

BORGES, Roxana Cardoso Brasileiro. Função ambiental do contrato: proposta de operacionalização do princípio civil para a proteção do meio ambiente. Revista de Direito Ambiental, v. 49, p. 228-246, 2008.

DAIBERT, Jefferson. Direito das Coisas. 2. ed. Rio de Janeiro: Forense, 1979.

DANTAS, F.C. de San Tiago. O conflito de vizinhança e sua composição. Rio de Janeiro: [s.n.], 1939.

DERANI, Cristiane. Direito ambiental econômico. 3. ed. São Paulo: Saraiva, 2009.

FIORILLO, Celso Antonio Pacheco. Curso de direito ambiental brasileiro.

4. ed. São Paulo: Saraiva, 2003.

GOMES, Daniela Vasconcellos. Considerações acerca do direito fundamental ao meio ambiente sadio e ecologicamente equilibrado. Revista de Direito Ambiental, Editora Revista dos Tribunais, ano 14, n. 55, p. 25-51, jul./set. 2009.

HABER, Lilian Mendes. O sobreprincípio da soberana qualidade de vida. Revista de Direito Ambiental, Editora Revista dos Tribunais, ano 14, n. 55, p. 87-117, jul./set. 2009.

LACERDA, Adriana Bender Moreira de; MAGNI, Cristiana; MORATA, Thais Catalani; MARQUES, Jair Mendes; ZANNIN, Paulo Henrique Trombetta. Ambiente Urbano e Percepção da Poluição Sonora. Disponível em: <http://www.scielo.br/pdf/asoc/v8n2/28606.pdf>. Acesso em: 16 jul. 2018.

MARÉS, Carlos Frederico. A função social da terra. Porto Alegre: Sergio Antonio Fabris Editor, 2003.

MENDES, Gilmar Ferreira; COELHO, Inocêncio Mártires; BRANCO, Paulo Gustavo Gonet. Curso de direito constitucional. 4. ed. rev. e atual. São Paulo: Saraiva, 2009.

MIRANDA, Pontes de. Tratado de direito privado: parte especial. 2. ed. Rio de Janeiro: Borsoi, 1956.

MONTEIRO FILHO, Carlos Edison do Rêgo. O direito de vizinhança no novo código civil. Revista da EMERJ, Rio de Janeiro, p. 158-167, jul./2002 - abr./2003. Edição especial, parte 2. 
Disponível em:

<http://www.emerj.tjrj.jus.br/revistaemerj_online/edicoes/anais_onovocodigocivil/anais_especial _2/Anais_Parte_II_revistaemerj_158.pdf>. Acesso em 19 jul. 2018.

MONTEIRO, Washington de Barros. Curso de direito civil. 32. ed., rev. e atual São Paulo: Saraiva, 2003.

NEPOMUCENO, Luiza de Arruda. Elementos de acústica física e psicoacústica. São Paulo: E. Blucher, 1994.

PRESTES, Vanêsca Buzelato. A função social da propriedade nas cidades: das limitações administrativas ao conteúdo da propriedade. Revista Magister de Direito Ambiental e Urbanístico, Porto Alegre (RS), ano II, n. 18, p. 15-48, jun. -jul. 2008.

RODRIGUES, Silvio. Direito Civil: direito das coisas, vol. 5. 28. ed. rev. e atual. de acordo com o novo Código Civil (Lei n. 10.406, de 10.1.2002). São Paulo: Saraiva, 2003.

SARMENTO, Daniel (Org). Interesses públicos versus interesses privados: desconstruindo o princípio de supremacia do interesse público. 1. ed. Rio de Janeiro: Lumen Juris, 2005.

TEPEDINO, Gustavo. Temas de Direito Civil. 2. ed. rev. e atual. Rio de Janeiro: Renovar, 2001.

WORLD HEALTH ORGANIZATION (Organização Mundial de Saúde). Noise. Disponível em: < http://www.euro.who.int/en/what-we-do/health-topics/environment-and-health/noise>. Acesso em 16 jul. 2018.

Revista Brasileira de Direito Civil em Perspectiva | e-ISSN: 2526-0243| Porto Alegre | v. 4 | n. 2 |

p. 39-61 | Jul/Dez. 2018 